\title{
Don't just swallow, check the evidence first
}

\author{
Fiona Godlee editor, BMJ
}

Some of you will have seen an advertisement on bmj.com in recent weeks from Hydration for Health. It's a campaign, sponsored by the producers of Volvic, Evian, and Badoit bottled waters, to get us all to drink more water. What's this doing in a medical journal? The campaign website explains that encouraging "healthy hydration" should be part of routine patient counselling because "evidence is increasing that even mild dehydration plays a role in the development of various diseases."

But what and where is this evidence? Alerted to the ads by general practitioner and $B M J$ columnist Margaret McCartney, we discovered that we hadn't followed our own guidelines (http: //bit.ly/pSPdgk). The advertisement bypassed our editorial checks, so we didn't ask the advertiser, Danone, to provide peer reviewed, published research articles in support of their statements. We've now done this.

It seems unlikely that Danone will be able to deliver what we need. In an article in this week's $B M J$, McCartney picks through the references used to support the idea that we don't drink enough water (doi:10.1136/bmj.d4280). She finds them sadly lacking. Some refer to discussion papers rather than primary research, others to low level observational studies.

Yet Danone is not alone in saying we should drink more. All kinds of organisations recommend drinking eight glasses of water a day, including the NHS on its NHS Choices website. "This is not only nonsense, but is thoroughly debunked nonsense," says McCartney. Some patients may benefit from drinking more water-those with recurrent kidney stones and polycystic kidney disease for example. But she concludes that there is no clear evidence either for or against telling everyone to do so. And then there are all those bottles.
Contrast this evidence-lite approach with the rigorous, evidence based, consultative, and transparent methods of the Norwegian primary prevention guidelines group. Worried by the fact that European guidelines classified almost all older people as being at high risk of cardiovascular disease, Norway has developed its own guidelines that use differential risk thresholds according to age. In this week's $B M J$ the guideline's authors, Ole Norheim and colleagues, describe how they did this (doi:10.1136/bmj. d3626).

Instead of adopting existing algorithms for estimating risk, such as the QRISK or Framingham cardiovascular risk scores, which have not been validated in Norway, the guideline team developed their own using data from Norwegian patients. Whereas the European guidelines give a single threshold for starting medication-at an absolute risk of cardiovascular death $\geq 5 \%$, the Norwegian guidelines give three different thresholds for patients aged up to 49, 59, and 69 years. This shifts the emphasis of treatment from older to younger people. "Compared with the European guidelines, the total sum of life gained is about the same, but the number of patients treated is considerably lower," they say.

This approach has to be better for Norwegians and their health system. What can other countries learn from it?

Listen to Margaret McCartney discussing Hydration for Health in a podcast at http://bit.ly/r4fMIC

Cite this as: $B M J 2011 ; 343: \mathrm{d} 4478$ 